Published in final edited form as:

Coron Artery Dis. 2015 May ; 26(3): 231-238. doi:10.1097/MCA.0000000000000208.

\title{
Predictive Value of Endothelial Function by Non-invasive Peripheral Arterial Tonometry for Coronary Artery Disease
}

\author{
Yasushi Matsuzawa, MD, PhD ${ }^{1}$, Jing Li, MD, PhD ${ }^{1}$, Tatsuo Aoki, MD, PhD ${ }^{1}$, Raviteja R. \\ Guddeti, MD ${ }^{1}$, Taek-Geun Kwon, MD, PhD ${ }^{1}$, Rebecca Cilluffo, MD ${ }^{1}$, R. Jay. Widmer, MD, \\ $\mathrm{PhD}^{1}$, Rajiv Gulati, MD, $\mathrm{PhD}^{1}$, Ryan J. Lennon, $\mathrm{MS}^{2}$, Lilach O. Lerman, $\mathrm{MD}, \mathrm{PhD}^{3}$, and $\mathrm{Amir}$ \\ Lerman, MD $^{1}$ \\ ${ }^{1}$ Division of Cardiovascular Diseases, Mayo Clinic, Rochester, MN, USA \\ ${ }^{2}$ Biomedical Statistics and Informatics, Mayo Clinic, Rochester, MN, USA \\ ${ }^{3}$ Division of Nephrology and Hypertension, Mayo Clinic, Rochester, MN, USA
}

\begin{abstract}
Background-Endothelial dysfunction is a key step in the initiation and progression of atherosclerosis and subsequent cardiovascular complications. We examined whether peripheral endothelial function, as assessed by fingertip reactive hyperemia-peripheral arterial tonometry (RH-PAT) can provide additional clinical value to traditional risk factors for cardiovascular diseases in predicting coronary artery disease (CAD).
\end{abstract}

Methods-We included 118 stable patients who were referred for coronary angiography for chest pain evaluation or abnormal stress test. A natural logarithmic value of RH-PAT index (Ln_RHI) was obtained before cardiac catheterization by an independent operator. Significant CAD was defined as luminal stenosis $\geq 70 \%$ ( $250 \%$ at left main) and/or fractional flow reserve $\unlhd$ 0.80 in one or more major coronary arteries or their major branches.

Results-Levels of Ln_RHI were significantly lower in patients with CAD ( $\mathrm{n}=60)$ compared to patients without CAD ( $\mathrm{n}=58)(0.69 \pm 0.29$ vs. $0.88 \pm 0.27$, p<0.001). Ln_RHI was significantly associated with CAD independent from traditional risk factors (odds ratio [OR] for 0.1 decrease in Ln_RHI $1.25,95 \%$ confidence interval [CI] 1.04 to 1.52 , p=0.01). The net reclassification index was improved when Ln_RHI was added to traditional risk factors $(0.62,95 \%$ CI: 0.27 to 0.97 , $\mathrm{p}=0.001)$.

Conclusions-Peripheral endothelial function, as assessed by RH-PAT, improved risk stratification when added to traditional risk factors. RH-PAT is potentially useful for identifying patients at high risk for CAD.

\section{Keywords}

coronary artery disease; endothelial function; coronary risk factor

\footnotetext{
Address for correspondence: Amir Lerman MD, Division of Cardiovascular Disease and Department of Internal Medicine, Mayo College of Medicine, 200 First Street SW, Rochester, MN, 55905, USA, Phone: 507-255-4152, Fax: 507-255-2550,

lerman.amir@mayo.edu.

Conflict of interest: Author A.L. declared consulting for Itamar Medical.
} 


\section{Introduction}

Although modification of conventional coronary risk factors and lifestyle behavior has reduced its incidence, coronary artery disease (CAD) continues to be one of the most common chronic illnesses in the United States and the developed world.

Practice guidelines recommend approaches using Framingham Risk Score (FRS) or other similar risk prediction models. ${ }^{1}$ Traditional risk factors overall are however, thought to account for only $50 \%$ of CAD events, indicating the presence of unknown risk factors for atherosclerosis. ${ }^{2}$ Endothelial dysfunction is considered a key step in the initiation and progression of atherosclerosis and cardiovascular complications. Endothelial function could be a functional expression of the overall cardiovascular risk factors burden that reacts the sum of all vasculoprotective factors and a parameter of activity of the disease. ${ }^{2}$ Direct invasive assessment of coronary endothelial dysfunction by vasoconstrictive response to the endothelium-dependent vasodilator acetylcholine was shown to be a strong predictor of cardiac events, but is too invasive to employ routinely. ${ }^{3}$

Reactive hyperemia-peripheral arterial tonometry (RH-PAT) is a non-invasive, automated, quantitative clinical test used for the evaluation of peripheral endothelial function. ${ }^{4} \mathrm{RH}-$ PAT, as well as brachial artery flow mediated dilation (FMD), use reactive hyperemia after forearm occlusion as a trigger to detect endothelium-dependent vasodilation. FMD represents conduit artery vasodilation, whereas RH-PAT represents microvessel vasodilation. The main advantage of RH-PAT technique is that the contralateral arm serves as its internal control that can be used to correct for any systemic changes during the test, in distinction with FMD. Moreover, RH-PAT technique is easy to use and less operator dependent. ${ }^{5}$ Clinical usefulness of RH-PAT has been reported in several studies. RH-PAT value was recently shown to be related to multiple traditional risk factors, ${ }^{6}$ as well as to mental stress ${ }^{7}$ as well as sleep disordered breathing ${ }^{8}$ which are considered novel risk factors for cardiovascular disease. Peripheral endothelial function, as assessed by RH-PAT, identifies invasively proven coronary endothelial dysfunction, ${ }^{9}$ and ischemic heart disease, ${ }^{10}$ and predicts future cardiovascular events. ${ }^{11,12}$ Thus, functional vascular response, as evaluated by RH-PAT, may serve as a surrogate marker for identifying patients with CAD. However, the clinical value of RH-PAT in addition to the established cardiovascular risk factors in identifying patients with advanced coronary plaques is still unclear.

This study was designed to investigate the relationship between the presence of CAD and peripheral endothelial function and to assess the additional value of RH-PAT to traditional risk factors as a non-invasive tool identifying individuals with CAD.

\section{Methods}

\section{Study design, setting and patients}

In this prospective, observational study, consecutive patients who were referred to Mayo Clinic, Rochester, MN, USA, for elective coronary angiography for chest pain evaluation or abnormal stress test were included between September 2010 and April 2012. All patients 
underwent RH-PAT examination followed by coronary angiography on the same day, and informed consent was obtained before initiating the study. The study protocol was approved by the Mayo Clinic institutional review board.

\section{RH-PAT}

Peripheral endothelial function was assessed in the fasting state before coronary angiography using RH-PAT (Itamar Medical Ltd., Caesarea, Israel). The RH-PAT method has been previously described. ${ }^{6,9}, 10,13-15$ A blood pressure cuff is placed on one upper arm, while the contralateral arm serves as a control. Peripheral arterial tonometry probes are placed on one finger of each hand. After a 5-minute equilibration period, the blood pressure cuff is inflated to $60 \mathrm{mmHg}$ above systolic pressure or $200 \mathrm{mmHg}$ for 5-minutes, and then deflated, inducing reactive hyperemia. RH-PAT data is analyzed by a computer in an operator-independent manner. As a measure of reactive hyperemia, the RH-PAT index (RHI) is calculated as the ratio of average amplitude of the PAT signal over a 1-minute time interval, starting 1.5 minutes after cuff deflation, divided by its average amplitude over a 2.5-minute time period before cuff inflation (baseline) through a computer algorithm automatically normalizing for baseline signal and indexed to the contralateral arm. Previous studies have demonstrated good reproducibility of the RH-PAT data recorded by this procedure. $^{14,16,17}$

\section{Coronary angiography}

Coronary angiography was performed by a standard technique using 4-7 French right and left catheters through a femoral or radial approach. Severity of coronary lesions was visually determined by independent cardiologists performing the procedure, blinded to the results of RH-PAT. Fractional flow reserve measurement was performed with a standard method ${ }^{18}$ using a 0.014-inch pressure monitoring guide-wire (Wave Wire, Volcano, Rancho Cordova, CA, USA) for all lesions that had been judged equivocal by the operator at the time of coronary angiography. Clinically significant $\mathrm{CAD}$ was defined by the presence of a coronary lesion resulting in a luminal stenosis $\geq 70 \%$ ( $250 \%$ at left main) or fractional flow reserve $₫ 0.80$ in one or more major coronary arteries or their major branches. ${ }^{19}$

\section{Coronary risk factors and FRS}

Risk factors were defined as current smoking (within one month), hypertension (arterial blood pressure $>140 / 90 \mathrm{mmHg}$ or antihypertensive medication), diabetes mellitus (patients history and/or need for insulin or oral hypoglycemic agents), and presence of a family history of cardiovascular disease in first-degree male relatives $<55$ or $<65$ years (female). The ten-year risk of coronary heart disease was calculated using a Framingham risk scoring system. This model includes age, total and high density lipoprotein (HDL) cholesterol, blood pressure, diabetes, and smoking and was designed in the setting of a community based cohort (Framingham, MA). ${ }^{20}$

\section{Statistical analysis}

We used a natural logarithmic transformation of RHI (Ln_RHI) because of its skewed distribution, and the median value of Ln_RHI (0.75846) was used to divide patients into two 
groups (high and low Ln_RHI). Continuous variables were presented as mean \pm standard deviation or median (interquartile range). Differences between continuous variables were analysed using unpaired t-test or Mann-Whitney $U$ test, as appropriate. Categorical variables were presented as frequencies and percentages, and intergroup comparisons were analysed by Fisher's exact test. Associations between the presence of CAD and cardiovascular risk factors were analyzed by univariate and multivariate logistic regression analyses with a forced entry method. We created two models to evaluate the additional value of $\mathrm{Ln} \_$RHI; (Model-1; age, gender, body mass index 230 , current smoking, hypertension, diabetes mellitus, total cholesterol, high-density lipoprotein cholesterol, and triglycerides) (Model-2; FRS). Receiver operating characteristic (ROC) curves were constructed for Model-1 and -2, and combination with Ln_RHI. Area under the curves (AUCs) (C statistics) were calculated to assess the ability to detect subjects with CAD and to detect subjects with coronary revascularization. A C statistic value of 0.5 indicates that the model is no better than chance, while a value of 1.0 indicates that the model has perfect discrimination. The usual thresholds were considered: $\searrow 0.7$; good discrimination, $\searrow 0.8$; very good, and $\searrow 0.9$; excellent.

Considering that $\mathrm{C}$ statistic is insensitive to further improvements in prediction once a good prediction model has been built, ${ }^{21}$ we did not assess the difference between $\mathrm{C}$ statistics. To overcome the limitations of $\mathrm{C}$ statistic, increased discriminative value after the addition of Ln_RHI to Model-1 and -2 were estimated using the net reclassification index (NRI). ${ }^{21}$ The category-free NRI was used in this study because established a priori risk categories do not exist. ${ }^{22}$ Briefly, the predicted event rate of CAD or revascularization using Model-1 or -2 alone was subtracted from the predicted event rate of CAD or revascularization using Model-1 or -2 plus Ln_RHI for each subject. The category-free NRI statistic is calculated as the net proportion of case patients for whom the risk with the expanded model is higher than the risk with the baseline model plus the net proportion of control subjects for whom the risk with the expanded model is lower than the risk with the baseline model. This metric does not require the specification of categories of risk and relies on the proportions of patients with events correctly assigned a higher model probability after adding the new biomarker to the model and patients without events correctly assigned a lower model probability after adding the new biomarker. Thus, NRI $=0.5$ indicates the new model improves risk prediction in $50 \%$ of entire subjects. A 2-sided P value of $<0.05$ was considered statistically significant. All analyses were performed using JMP version 9.0.0 (SAS Institute, Inc. Cary, NC) and SAS 9.3 software (SAS Institute, Inc. Cary, NC).

\section{Results}

\section{Patients}

One hundred and nineteen patients were included initially, with one patient subsequently excluded due to a poor quality signal of RH-PAT (Figure 1). Eventually, 118 patients were included in the study. After baseline evaluation which included RH-PAT examination, coronary angiography was performed in all the patients. Sixty (50.8\%) had significant CAD (single-vessel in 36 and multi-vessel in 24) of whom 50 patients underwent coronary revascularization (34 percutaneous coronary intervention and 16 coronary artery bypass grafting). The rest received medical management alone. Fractional flow reserve measurements were performed in 3 patients, and 2 of these were diagnosed as having 
significant CAD according to fractional flow reserve results. The mean FRS was $12.9 \pm 9.1 \%$, and was significantly higher in patients with CAD than those without (15.6 \pm 9.8 vs. $10.1 \pm 7.3, \mathrm{p}<0.001)$.

The overall mean age of all subjects was $62.7 \pm 11.4$ years, with a male predominance $(74 \%)$. Table 1 summarizes patient characteristics and concomitant medication use according to Ln_RHI value. The group with Ln_RHI below the median had more frequent male sex ( $84.8 \%$ vs. $62.7 \%, \mathrm{p}=0.01)$, diabetes $(33.9 \%$ vs. $8.5 \%, \mathrm{p}=0.001)$, and concomitant use of anti-diabetic drugs $(27.1 \%$ vs. $6.8 \%, \mathrm{p}=0.006)$ than the group with $\mathrm{Ln} \_$RHI above the median. Patients with lower Ln_RHI also had lower systolic blood pressure (124 \pm 14 vs. $131 \pm 17 \mathrm{mmHg}, \mathrm{p}=0.02$ ), and higher glucose level [105 (94 to 135) vs. 98 (91 to 107) mg/dl, $\mathrm{p}=0.01]$ compared with those with higher Ln_RHI. More patients in the group with lower Ln_RHI were diagnosed as having significant CAD by coronary angiography $(69.5 \%$ vs. $32.2 \%$, respectively, $\mathrm{p}<0.001)$ and required coronary revascularization $(52.5 \%$ vs. $32.2 \%$, respectively, $\mathrm{p}=0.04)$. Patients with $\mathrm{CAD}$ and patients with revascularization had significantly lower Ln_RHI levels (Figure 2). Although the difference was not significant, multi vessel disease slightly tended to be more frequently observed in the lower compared with the higher Ln_RHI group (27.1\% vs. $13.6 \%$, p=0.11).

\section{Factors associated with coronary artery disease}

In univariate logistic regression analysis, male sex, smoking, diabetes, higher glucose, lower HDL cholesterol, higher triglycerides, use of aspirin, higher FRS, and lower Ln_RHI were all significantly associated with the presence of CAD (Table 2). To evaluate the dependency of $\mathrm{Ln} \_\mathrm{RHI}$ on established cardiovascular risk factors in relation to the presence of CAD, we conducted multivariate logistic regression analyses. In both Model-1 (adjusted for traditional risk factors for cardiovascular disease) and Model-2 (adjusted for the FRS), Ln_RHI was significantly associated with the presence of CAD [odds ratio for 0.1 decrease in Ln_RHI (95\% confidence interval), Model-1; 1.25 (1.04 to 1.52), $\mathrm{p}=0.01$, Model-2; 1.30 (1.12 to 1.54), p<0.001, Table 3]. In multivariate logistic regression analysis, FRS and Ln_RHI showed borderline significance in identifying patients in need of coronary revascularization [odds ratio (95\% confidence interval), 1 point increase in FRS; 1.04 (0.99 to 1.09), $\mathrm{p}=0.056$, 0.1 decrease in Ln_RHI; 1.15 (1.00 to 1.33 ), p=0.050].

\section{Incremental effect of adding Ln_RHI for predicting CAD}

The $\mathrm{C}$ statistics increased for prediction of CAD when Ln_RHI was incorporated into traditional risk factors (Model-1) (from 0.80 to 0.82 ) and FRS (Model-2) (from 0.68 to 0.75) (Figure 3). The NRI was significant with the addition of Ln_RHI to risk factors (index, 0.26 for patients with $\mathrm{CAD}, 0.36$ for patients without $\mathrm{CAD}$, and 0.62 for overall, $\mathrm{p}=0.001$ ) and FRS (index, 0.37 for patients with CAD, 0.28 for patients without CAD, and 0.64 for overall, $\mathrm{p}<0.001)$ (Table 4).

We also evaluated the incremental effect of adding Ln_RHI to identify patients who required coronary revascularization. The $\mathrm{C}$ statistics increased for prediction of revascularization when Ln_RHI was incorporated into Model-1 (from 0.71 to 0.73 ) and FRS (from 0.62 to 0.66 ). The NRI was significant with the addition of Ln_RHI to Model-1 
(index, 0.23 for patients with revascularization, 0.24 for patients without revascularization, and 0.48 for overall, $\mathrm{p}=0.013$ ) and was borderline significant when added to FRS (index, 0.20 for patients with revascularization, 0.15 for patients without revascularization, and 0.35 for overall, $\mathrm{p}=0.063$ ) (Table 4).

\section{Discussion}

Our current study demonstrates that patients with CAD have attenuated peripheral endothelial function, as measured by RH-PAT, compared to those without CAD. Adding Ln_RHI to the established cardiovascular risk factors and FRS significantly augments risk stratification, as evidenced by NRI, suggesting that the addition of non-invasive assessment of peripheral endothelial function could be clinically valuable for identifying patients with CAD.

Many studies have demonstrated the crucial role of endothelial dysfunction in the pathogenesis of atherosclerosis and cardiovascular diseases. ${ }^{23-27}$ The RH-PAT device is Food and Drug Administration (FDA)-approved for assessing peripheral endothelial function. ${ }^{4}{ }^{15}$ RH-PAT technique has been demonstrated to be satisfactorily reproducible, ${ }^{13}, 14,16,28$ and the relations with cardiovascular risk factors, ${ }^{6}$ coronary endothelial dysfunction, ${ }^{9}$ and cardiovascular events, ${ }^{11,12,28}$ have been reported. Taken together, measurement of peripheral vasodilator response with a fingertip PAT device is potentially useful in clinical cardiovascular medicine. The Framingham Heart Study reported no statistically significant relation between RH-PAT and FMD, and concluded that these 2 methods have differing relations with cardiovascular risk factors. ${ }^{29}$ Although it has been reported that nitric oxide bioavailability plays a substantial role in both these methods, ${ }^{30,31}$ other substances, such as prostaglandin, adenosine hydrogen peroxide, can also affect vasodilation in response to shear stress and ischemia. ${ }^{32}$ Interestingly, although FMD, with proximal placement of occlusion cuff, elicits the production of a range of vasodilators compared to the one with distal cuff placement which is more NO dependent, FMD with proximal occlusion is more predictive for cardiovascular events. ${ }^{33}$ Moreover, it has been reported that microvascular function measured by blood flow or shear stress response after cuff release possesses independent predictive value, and such responses are not solely NO mediated. ${ }^{34-37}$ FMD and RH-PAT might reflect distinct aspects of vascular function complementarily. This study is the first to show significant incremental value for adding non-invasive endothelial function assessment by RH-PAT to the established cardiovascular risk factors and FRS in identifying obstructive CAD among patients complaining of chest pain as evidenced by NRI, suggesting that the assessment of endothelial function using RH-PAT can be an effective clinical tool to improve cardiovascular practice. A part of our study patients without significant CAD might have early coronary atherosclerosis or coronary spasm. As reported previously, compared to healthy population, RH-PAT values in patients with coronary abnormalities or multiple cardiac risk factors may be impaired, $, 9,38,39$ nonetheless the present study demonstrated the substantial predictive value of endothelial function for clinically significant obstructive CAD. Furthermore, with current data and relatively small number of patients and ROC analysis given, it seems that practical implementation of the test is indeed possible for risk estimation based on good C statistics (0.75-0.82), which are not much different from the 
predictive value of coronary calcium score to predict CAD ${ }^{40,41}$ However, the exact cut-off recommended for Ln_RHI to identify CAD is still unknown given the overlap in RHI values between the two groups (with and without CAD).

An obstructive plaque in a coronary artery is an anatomic marker of advanced atherosclerosis, which generally requires prolonged time course to progress, whereas attenuation in RH-PAT is a physiological vascular disorder which may be reversible 13,39, 42, 43 and involved in early and all steps of atherosclerosis. Endothelial dysfunction is considered an integrated index of all atherogenic and atheroprotective factors currently present in an individual. In this study, we demonstrated the additional predictive value of RH-PAT to traditional risk factors for identifying the patients at high-risk for obstructive CAD. Furthermore, a recent study reported that RH-PAT evaluation improved prognostic risk discrimination for future cardiovascular events when added to the FRS and coronary plaque complexity assessment in high risk patients including those with obstructive CAD. ${ }^{12}$ Kitta et al showed that patients with CAD and endothelial dysfunction, as assessed by FMD, have better cardiovascular prognosis if their endothelial function improved after 6 months of optimized therapy compared with patients who had persistent impairment of their endothelial function. ${ }^{44}$ Hence, given its reversibility $13,39,42,43$ and the availability of this diagnostic tool to identify patients at risk and to control the efficacy of therapy in clinical practice, endothelial dysfunction may be an attractive primary target in the effort to optimize individualized therapeutic strategies to reduce cardiovascular morbidity and mortality.

\section{Strength and limitation of the study}

The strength of this study includes that endothelial function was prospectively collected on the same day of coronary angiography, and blinded to physicians performing coronary angiography. Although the patients were studied prospectively and consecutively, all the study subjects underwent coronary angiography for clinically suspected CAD. Therefore, selection bias may affect the results. Second, although withdrawal of medications would be impractical and unethical, drugs may influence endothelial function. Third, we adopted the FRS as one of the baseline models to assess probability of atherosclerosis. However FRS has been established as a tool to calculate the risk of CAD at 10 years. Fourth, it was reported that non-obstructive CAD including coronary spastic angina, microvascular spasm, and microcirculatory insufficiency were also associated with attenuated endothelial function. ${ }^{10}$ In this study, acetylcholine provocation test was performed in only 2 patients to evaluate clinically suspected coronary spasm. Of these, one patient was diagnosed as coronary spastic angina and the peripheral endothelial function was low $($ Ln_RHI $=0.5766)$. We might underestimate the prevalence of non-obstructive CAD in this study.

\section{Conclusions}

Attenuated Ln_RHI, a non-invasive marker of systemic endothelial dysfunction, successfully identified obstructive $\mathrm{CAD}$, and its addition to established risk factors significantly improved risk classification for the presence of CAD. These results suggest that systemic endothelial dysfunction may reflect the presence of advanced coronary atherosclerotic plaque. 


\section{Acknowledgments}

Funding Sources: This work was supported by the National Institute of Health (NIH Grants HL-92954 and AG-31750), the Mayo Foundation, and a research fellowship from Banyu Life Science Foundation International (Y.M. and A.T.).

Role of the Sponsors: Banyu Life Science Foundation Internationa and the National Institute of Health had no role in the process of designing, implementing, and reporting of the study apart from its financial contribution, nor in drafting of the manuscript.

\section{References}

1. Goff DC Jr, Lloyd-Jones DM, Bennett G, Coady S, D'Agostino RB Sr, Gibbons R, et al. 2013 ACC/AHA Guideline on the Assessment of Cardiovascular Risk: A Report of the American College of Cardiology/American Heart Association Task Force on Practice Guidelines. Circulation. 2013

2. Reriani MK, Flammer AJ, Jama A, Lerman LO, Lerman A. Novel functional risk factors for the prediction of cardiovascular events in vulnerable patients following acute coronary syndrome. Circ J. 2012; 76:778-783. [PubMed: 22451445]

3. Suwaidi JA, Hamasaki S, Higano ST, Nishimura RA, Holmes DR Jr, Lerman A. Long-term followup of patients with mild coronary artery disease and endothelial dysfunction. Circulation. 2000; 101:948-954. [PubMed: 10704159]

4. Kuvin JT, Patel AR, Sliney KA, Pandian NG, Sheffy J, Schnall RP, et al. Assessment of peripheral vascular endothelial function with finger arterial pulse wave amplitude. Am Heart J. 2003; 146:168-174. [PubMed: 12851627]

5. Woo JS, Jang WS, Kim HS, Lee JH, Choi EY, Kim JB, et al. Comparison of peripheral arterial tonometry and flow-mediated vasodilation for assessment of the severity and complexity of coronary artery disease. Coron Artery Dis. 2014; 25:421-426. [PubMed: 24584030]

6. Hamburg NM, Keyes MJ, Larson MG, Vasan RS, Schnabel R, Pryde MM, et al. Cross-sectional relations of digital vascular function to cardiovascular risk factors in the Framingham Heart Study. Circulation. 2008; 117:2467-2474. [PubMed: 18458169]

7. Martin EA, Prasad A, Rihal CS, Lerman LO, Lerman A. Endothelial function and vascular response to mental stress are impaired in patients with apical ballooning syndrome. J Am Coll Cardiol. 2010; 56:1840-1846. [PubMed: 21087714]

8. Cereda CW, Tamisier R, Manconi M, Andreotti J, Frangi J, Pifferini V, et al. Endothelial dysfunction and arterial stiffness in ischemic stroke: the role of sleep-disordered breathing. Stroke. 2013; 44:1175-1178. [PubMed: 23471270]

9. Bonetti PO, Pumper GM, Higano ST, Holmes DR Jr, Kuvin JT, Lerman A. Noninvasive identification of patients with early coronary atherosclerosis by assessment of digital reactive hyperemia. J Am Coll Cardiol. 2004; 44:2137-2141. [PubMed: 15582310]

10. Matsuzawa Y, Sugiyama S, Sugamura K, Nozaki T, Ohba K, Konishi M, et al. Digital assessment of endothelial function and ischemic heart disease in women. J Am Coll Cardiol. 2010; 55:16881696. [PubMed: 20394872]

11. Rubinshtein R, Kuvin JT, Soffler M, Lennon RJ, Lavi S, Nelson RE, et al. Assessment of endothelial function by non-invasive peripheral arterial tonometry predicts late cardiovascular adverse events. Eur Heart J. 2010; 31:1142-1148. [PubMed: 20181680]

12. Matsuzawa Y, Sugiyama S, Sumida H, Sugamura K, Nozaki T, Ohba K, et al. Peripheral endothelial function and cardiovascular events in high-risk patients. J Am Heart Assoc. 2013; 2:e000426. [PubMed: 24275629]

13. Bonetti PO, Barsness GW, Keelan PC, Schnell TI, Pumper GM, Kuvin JT, et al. Enhanced external counterpulsation improves endothelial function in patients with symptomatic coronary artery disease. J Am Coll Cardiol. 2003; 41:1761-1768. [PubMed: 12767662]

14. Selamet Tierney ES, Newburger JW, Gauvreau K, Geva J, Coogan E, Colan SD, et al. Endothelial pulse amplitude testing: feasibility and reproducibility in adolescents. J Pediatr. 2009; 154:901905. [PubMed: 19217124] 
15. Kuvin JT, Mammen A, Mooney P, Alsheikh-Ali AA, Karas RH. Assessment of peripheral vascular endothelial function in the ambulatory setting. Vasc Med. 2007; 12:13-16. [PubMed: 17451088]

16. Brant LC, Barreto SM, Passos VM, Ribeiro AL. Reproducibility of peripheral arterial tonometry for the assessment of endothelial function in adults. J Hypertens. 2013; 31:1984-1990. [PubMed: 23751970]

17. McCrea CE, Skulas-Ray AC, Chow M, West SG. Test-retest reliability of pulse amplitude tonometry measures of vascular endothelial function: implications for clinical trial design. Vasc Med. 2012; 17:29-36. [PubMed: 22363016]

18. Pijls NH, De Bruyne B, Peels K, Van Der Voort PH, Bonnier HJ, Bartunek JKJJ, et al. Measurement of fractional flow reserve to assess the functional severity of coronary-artery stenoses. N Engl J Med. 1996; 334:1703-1708. [PubMed: 8637515]

19. Patel MR, Dehmer GJ, Hirshfeld JW, Smith PK, Spertus JA. ACCF/SCAI/STS/AATS/AHA/ ASNC/HFSA/SCCT 2012 Appropriate use criteria for coronary revascularization focused update: a report of the American College of Cardiology Foundation Appropriate Use Criteria Task Force, Society for Cardiovascular Angiography and Interventions, Society of Thoracic Surgeons, American Association for Thoracic Surgery, American Heart Association, American Society of Nuclear Cardiology, and the Society of Cardiovascular Computed Tomography. J Am Coll Cardiol. 2012; 59:857-881. [PubMed: 22296741]

20. Wilson PW, D'Agostino RB, Levy D, Belanger AM, Silbershatz H, Kannel WB. Prediction of coronary heart disease using risk factor categories. Circulation. 1998; 97:1837-1847. [PubMed: 9603539]

21. Pencina MJ, D'Agostino RB Sr, D'Agostino RB Jr, Vasan RS. Evaluating the added predictive ability of a new marker: from area under the ROC curve to reclassification and beyond. Stat Med. 2008; 27:157-172. discussion 207-112. [PubMed: 17569110]

22. Pencina MJ, D'Agostino RB Sr, Steyerberg EW. Extensions of net reclassification improvement calculations to measure usefulness of new biomarkers. Stat Med. 2011; 30:11-21. [PubMed: 21204120]

23. Pepine CJ. The impact of nitric oxide in cardiovascular medicine: untapped potential utility. Am J Med. 2009; 122:S10-15. [PubMed: 19393821]

24. Verma S, Buchanan MR, Anderson TJ. Endothelial function testing as a biomarker of vascular disease. Circulation. 2003; 108:2054-2059. [PubMed: 14581384]

25. Ludmer PL, Selwyn AP, Shook TL, Wayne RR, Mudge GH, Alexander RW, et al. Paradoxical vasoconstriction induced by acetylcholine in atherosclerotic coronary arteries. N Engl J Med. 1986; 315:1046-1051. [PubMed: 3093861]

26. Ross R. Atherosclerosis--an inflammatory disease. N Engl J Med. 1999; 340:115-126. [PubMed: 9887164]

27. Kinlay S, Ganz P. Role of endothelial dysfunction in coronary artery disease and implications for therapy. Am J Cardiol. 1997; 80:11I-16I. [PubMed: 9205012]

28. Akiyama E, Sugiyama S, Matsuzawa Y, Konishi M, Suzuki H, Nozaki T, et al. Incremental prognostic significance of peripheral endothelial dysfunction in patients with heart failure with normal left ventricular ejection fraction. J Am Coll Cardiol. 2012; 60:1778-1786. [PubMed: 23040568]

29. Hamburg NM, Palmisano J, Larson MG, Sullivan LM, Lehman BT, Vasan RS, et al. Relation of brachial and digital measures of vascular function in the community: the Framingham heart study. Hypertension. 2011; 57:390-396. [PubMed: 21263120]

30. Nohria A, Gerhard-Herman M, Creager MA, Hurley S, Mitra D, Ganz P. Role of nitric oxide in the regulation of digital pulse volume amplitude in humans. J Appl Physiol (1985). 2006; 101:545548. [PubMed: 16614356]

31. Meredith IT, Currie KE, Anderson TJ, Roddy MA, Ganz P, Creager MA. Postischemic vasodilation in human forearm is dependent on endothelium-derived nitric oxide. Am J Physiol. 1996; 270:H1435-1440. [PubMed: 8967386]

32. Loscalzo J, Vita JA. Ischemia, hyperemia, exercise, and nitric oxide. Complex physiology and complex molecular adaptations. Circulation. 1994; 90:2556-2559. [PubMed: 7955218] 
33. Green DJ, Jones H, Thijssen D, Cable NT, Atkinson G. Flow-mediated dilation and cardiovascular event prediction: does nitric oxide matter? Hypertension. 2011; 57:363-369. [PubMed: 21263128]

34. Joannides R, Bellien J, Thuillez C. Clinical methods for the evaluation of endothelial function-- a focus on resistance arteries. Fundam Clin Pharmacol. 2006; 20:311-320. [PubMed: 16671967]

35. Mitchell GF, Parise H, Vita JA, Larson MG, Warner E, Keaney JF Jr, et al. Local shear stress and brachial artery flow-mediated dilation: the Framingham Heart Study. Hypertension. 2004; 44:134139. [PubMed: 15249547]

36. Huang AL, Silver AE, Shvenke E, Schopfer DW, Jahangir E, Titas MA, et al. Predictive value of reactive hyperemia for cardiovascular events in patients with peripheral arterial disease undergoing vascular surgery. Arterioscler Thromb Vasc Biol. 2007; 27:2113-2119. [PubMed: 17717291]

37. Philpott AC, Lonn E, Title LM, Verma S, Buithieu J, Charbonneau F, et al. Comparison of new measures of vascular function to flow mediated dilatation as a measure of cardiovascular risk factors. Am J Cardiol. 2009; 103:1610-1615. [PubMed: 19463524]

38. Matsuzawa Y, Sugiyama S, Sugamura K, Nozaki T, Ohba K, Konishi M, et al. Digital assessment of endothelial function and ischemic heart disease in women. Journal of the American College of Cardiology. 2010; 55:1688-1696. [PubMed: 20394872]

39. Matsuzawa Y, Sugiyama S, Sugamura K, Sumida H, Kurokawa H, Fujisue K, et al. Successful diet and exercise therapy as evaluated on self-assessment score significantly improves endothelial function in metabolic syndrome patients. Circ J. 2013; 77:2807-2815. [PubMed: 23986029]

40. Haberl R, Becker A, Leber A, Knez A, Becker C, Lang C, et al. Correlation of coronary calcification and angiographically documented stenoses in patients with suspected coronary artery disease: results of 1,764 patients. J Am Coll Cardiol. 2001; 37:451-457. [PubMed: 11216962]

41. Budoff MJ, Diamond GA, Raggi P, Arad Y, Guerci AD, Callister TQ, et al. Continuous probabilistic prediction of angiographically significant coronary artery disease using electron beam tomography. Circulation. 2002; 105:1791-1796. [PubMed: 11956121]

42. Widmer RJ, Freund MA, Flammer AJ, Sexton J, Lennon R, Romani A, et al. Beneficial effects of polyphenol-rich olive oil in patients with early atherosclerosis. Eur J Nutr. 2013; 52:1223-1231. [PubMed: 22872323]

43. Matsubara J, Sugiyama S, Akiyama E, Iwashita S, Kurokawa H, Ohba K, et al. Dipeptidyl peptidase-4 inhibitor, sitagliptin, improves endothelial dysfunction in association with its antiinflammatory effects in patients with coronary artery disease and uncontrolled diabetes. Circ J. 2013; 77:1337-1344. [PubMed: 23386232]

44. Kitta Y, Obata JE, Nakamura T, Hirano M, Kodama Y, Fujioka D, et al. Persistent impairment of endothelial vasomotor function has a negative impact on outcome in patients with coronary artery disease. J Am Coll Cardiol. 2009; 53:323-330. [PubMed: 19161880] 


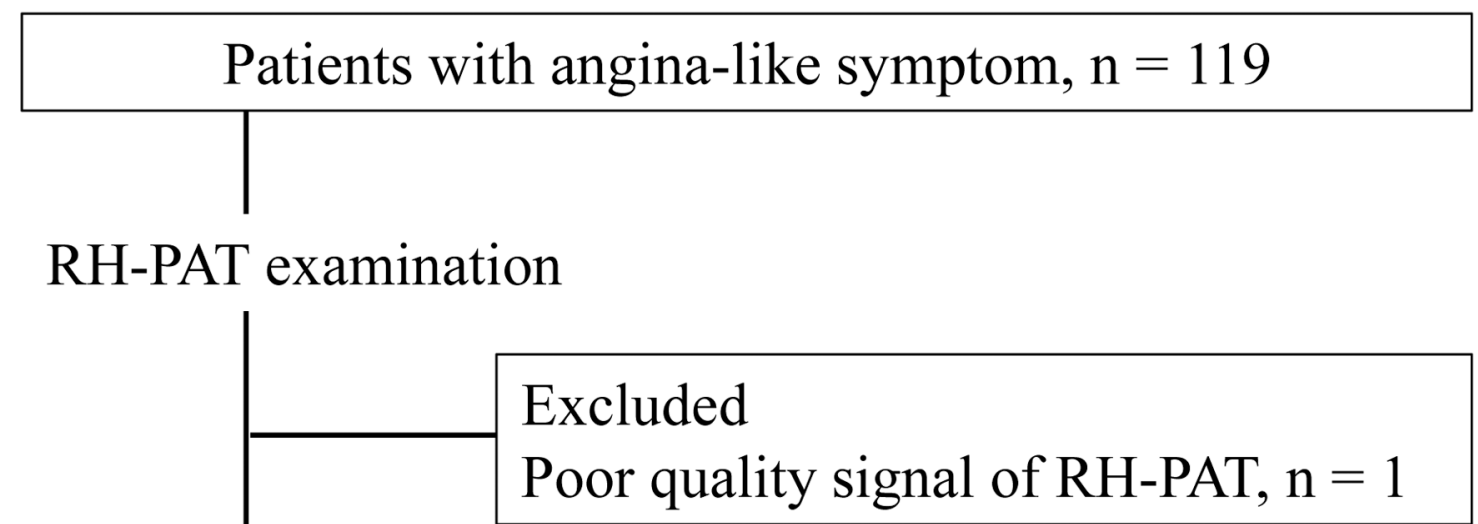

\section{Coronary angiography}

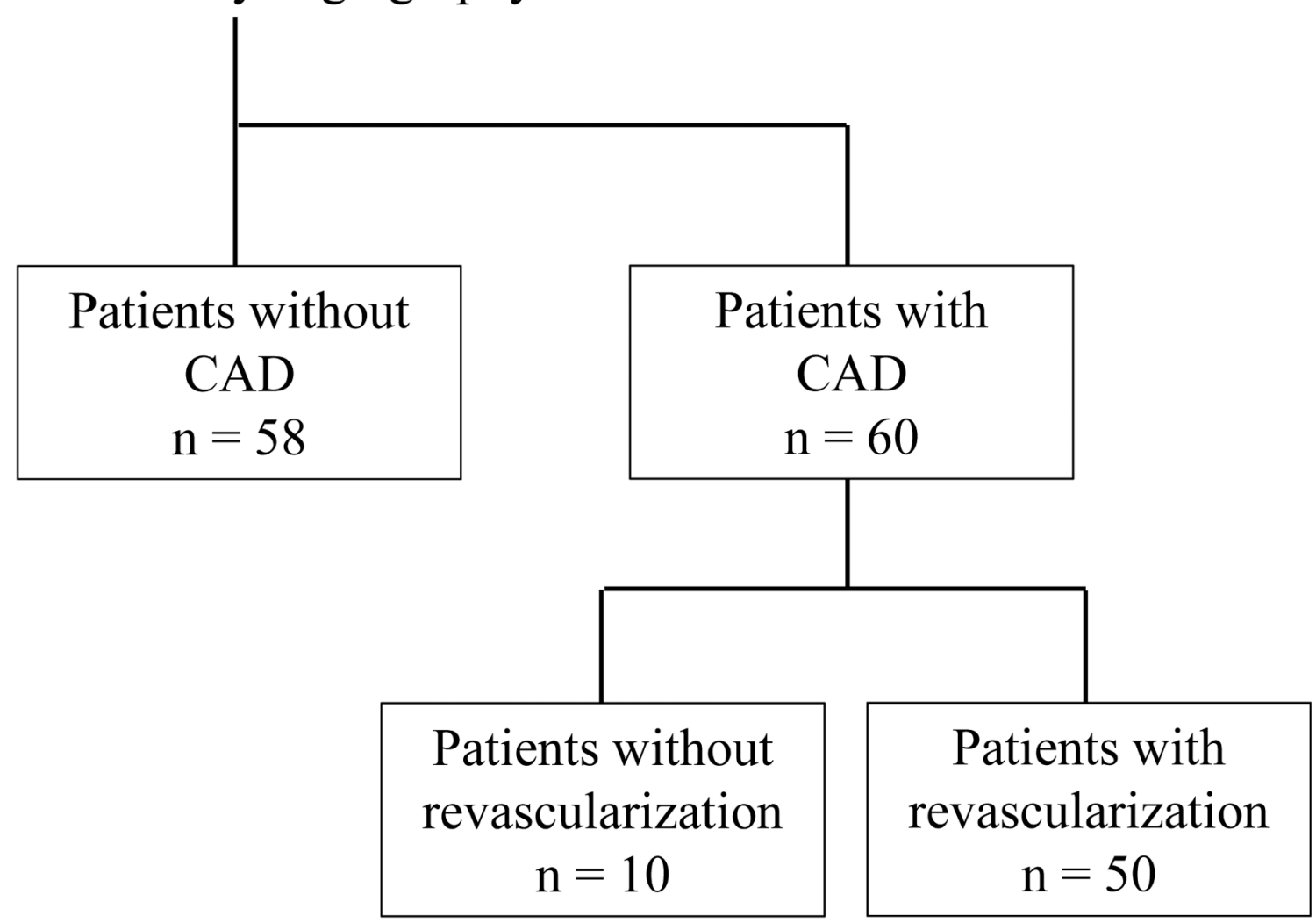

Figure 1. Study flow chart

CAD: coronary artery disease, and RH-PAT: reactive hyperemia-peripheral arterial tonometry. 
(A)

(B) index.
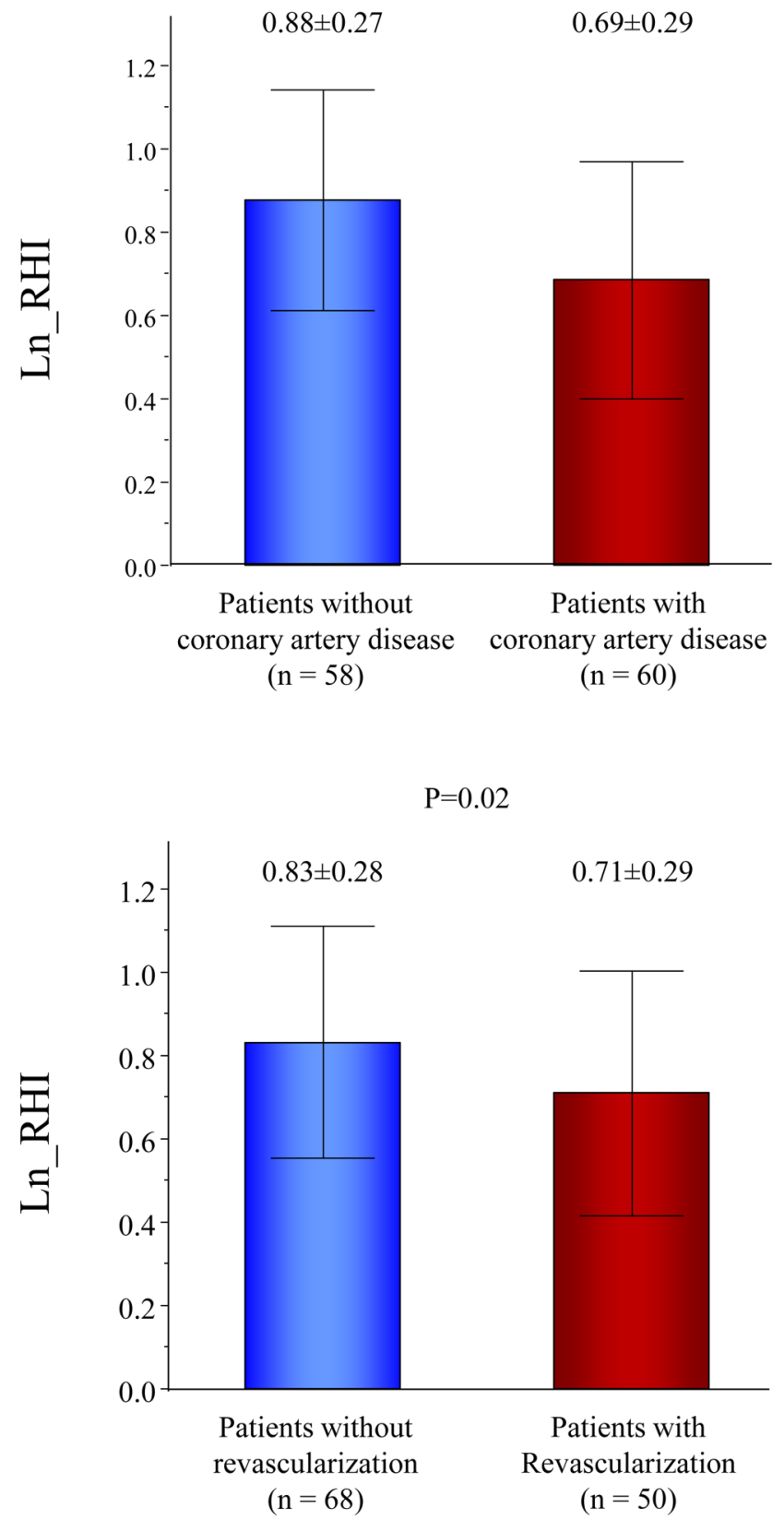

Figure 2. Ln_RHI levels according to coronary artery disease or coronary revascularization The boxes and error bars show mean values and standard deviations of Ln_RHI. Ln_RHI; natural logarithmic transformation of reactive hyperemia-peripheral arterial tonometry

Coron Artery Dis. Author manuscript; available in PMC 2016 May 01. 
(A)

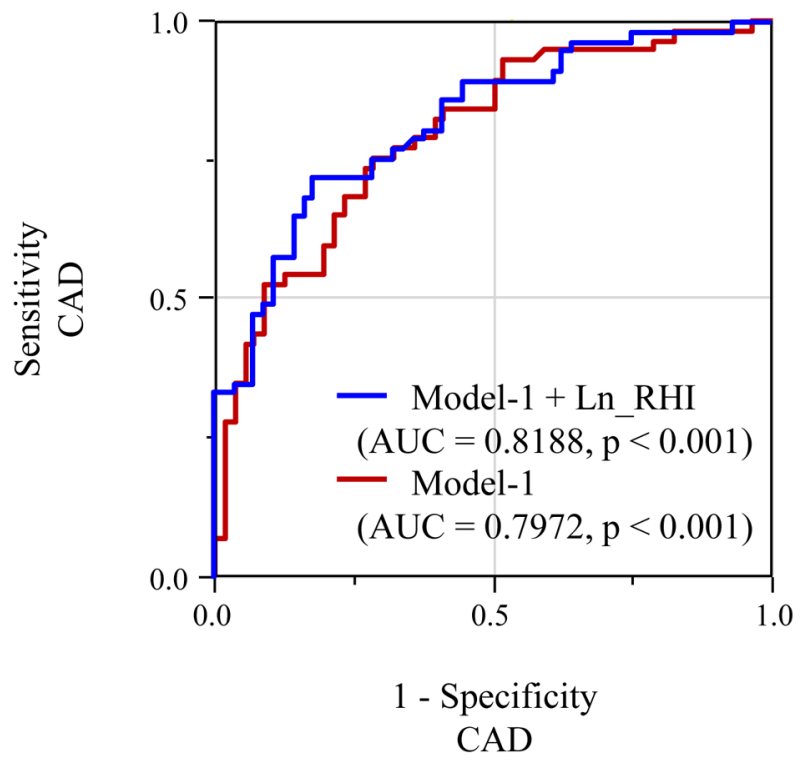

(B)

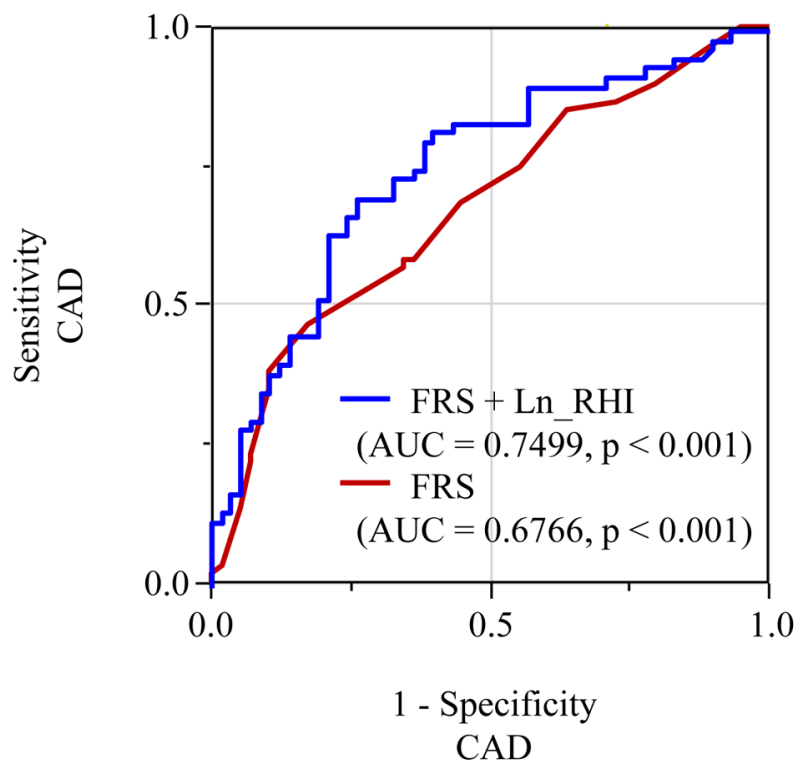

Figure 3. Receiver operating characteristic curves

Model-1 consists of gender, age, body mass index 230 , smoking, hypertension, diabetes mellitus, total cholesterol, high density lipoprotein cholesterol, ant triglycerides. AUC: area under the curve, CAD: coronary artery disease, and FRS: Framingham Risk Score. Other abbreviations as in Figure-2. 


\section{Table 1}

Baseline characteristics according to Ln_RHI group.

\begin{tabular}{|c|c|c|c|c|}
\hline & $\begin{array}{c}\text { All } \\
(n=118)\end{array}$ & $\begin{array}{c}\text { Low } \\
\text { Ln_RHI } \\
\text { group } \\
(n=59)\end{array}$ & $\begin{array}{c}\text { High } \\
\text { Ln_RHI } \\
\text { group } \\
(\mathbf{n}=59)\end{array}$ & $\mathbf{P}$ \\
\hline Age, mean $\pm S D, y$ & $62.7 \pm 11.4$ & $62.2 \pm 11.6$ & $63.2 \pm 11.3$ & 0.61 \\
\hline Male, n. (\%) & $87(73.7 \%)$ & $50(84.8 \%)$ & $37(62.7 \%)$ & $0.01^{*}$ \\
\hline Body mass index, mean \pm SD & $30.4 \pm 5.4$ & $31.0 \pm 5.1$ & $29.8 \pm 5.6$ & 0.24 \\
\hline Smoking, n. (\%) & $19(16.1 \%)$ & $10(17.0 \%)$ & $9(15.3 \%)$ & $>0.99$ \\
\hline Hypertension, n. (\%) & $69(58.5 \%)$ & $35(59.3 \%)$ & $34(57.6 \%)$ & $>0.99$ \\
\hline Diabetes, n. (\%) & $25(21.2 \%)$ & $20(33.9 \%)$ & $5(8.5 \%)$ & $0.001^{*}$ \\
\hline Family history of CAD, n. (\%) & $35(29.7 \%)$ & $17(28.8 \%)$ & $18(30.5 \%)$ & $>0.99$ \\
\hline Systolic blood pressure, , mean $\pm \mathrm{SD}, \mathrm{mmHg}$ & $128 \pm 16$ & $124 \pm 14$ & $131 \pm 17$ & $0.02 *$ \\
\hline Diastolic blood pressure, mean $\pm \mathrm{SD}, \mathrm{mmHg}$ & $73 \pm 10$ & $72 \pm 10$ & $74 \pm 9$ & 0.41 \\
\hline Glucose, median (IQR), mg/dl & $101(92-113)$ & $105(94-135)$ & $98(91-107)$ & $0.01^{*}$ \\
\hline Total cholesterol, mean $\pm \mathrm{SD}, \mathrm{mg} / \mathrm{dl}$ & $182 \pm 41$ & $182 \pm 45$ & $181 \pm 36$ & 0.86 \\
\hline HDL cholesterol, mean $\pm \mathrm{SD}, \mathrm{mg} / \mathrm{dl}$ & $48 \pm 14$ & $45 \pm 12$ & $50 \pm 15$ & 0.07 \\
\hline Triglycerides, median (IQR), mg/dl & $117(92-170)$ & $125(97-174)$ & $115(77-156)$ & 0.34 \\
\hline Creatinine, mean $\pm \mathrm{SD}, \mathrm{mg} / \mathrm{dl}$ & $0.98 \pm 0.26$ & $1.01 \pm 0.28$ & $0.96 \pm 0.24$ & 0.26 \\
\hline Statins, n. (\%) & $58(49.2 \%)$ & $30(50.9 \%)$ & $28(47.5 \%)$ & 0.85 \\
\hline Calcium channel blockers, n. (\%) & $10(8.5 \%)$ & $6(10.2 \%)$ & $4(6.8 \%)$ & 0.74 \\
\hline ACE-I or ARB, n. (\%) & $44(37.3 \%)$ & $25(42.4 \%)$ & $19(32.2 \%)$ & 0.34 \\
\hline Beta blockers, n. (\%) & $49(41.5 \%)$ & $28(47.5 \%)$ & $21(35.6 \%)$ & 0.26 \\
\hline Nitrate, n. $(\%)$ & $22(18.6 \%)$ & $8(13.6 \%)$ & $14(23.7 \%)$ & 0.23 \\
\hline Aspirin, n. (\%) & $74(62.7 \%)$ & $38(64.4 \%)$ & $36(61.0 \%)$ & 0.85 \\
\hline Anti-diabetic drugs, n. (\%) & $20(17.0 \%)$ & $16(27.1 \%)$ & $4(6.8 \%)$ & $0.006^{*}$ \\
\hline 10 years FRS, mean \pm SD, $\%$ & $12.9 \pm 9.1$ & $14.2 \pm 9.6$ & $11.6 \pm 8.3$ & 0.12 \\
\hline Ln_RHI, mean \pm SD & $0.78 \pm 0.29$ & $0.56 \pm 0.19$ & $1.00 \pm 0.20$ & \\
\hline
\end{tabular}

Patients were divided into two groups by the median value of Ln_RHI (0.75846). Data are expressed as mean \pm SD, median (IQR), or no. (\%). Significance was assessed between high and low Ln_RHI groups.

indicates $\mathrm{P}<0.05$.

ACE-I: angiotensin-converting enzyme-inhibitors, ARB: angiotensin II receptor blockers, CAD: coronary artery disease, FRS: Framingham Risk Score, HDL: high-density lipoprotein, IQR: interquartile range, RHI: reactive hyperemia-peripheral arterial tonometry index, and SD: standard deviation. 
Table 2

Univariate logistic regression analysis for the presence of CAD.

\begin{tabular}{lccc}
\hline & OR & $\mathbf{9 5 \%} \mathbf{C I}$ & $\mathbf{P}$ \\
\hline Male sex & 4.27 & $1.78-11.2$ & 0.001 \\
Age (per year) & 1.00 & $0.97-1.03$ & 0.96 \\
Body mass index $330 \mathrm{~kg} / \mathrm{m}^{2}$ & 1.31 & $0.64-2.72$ & 0.46 \\
Current smoking (yes) & 3.23 & $1.14-10.6$ & 0.03 \\
Hypertension (yes) & 1.31 & $0.63-2.74$ & 0.47 \\
Diabetes (yes) & 4.02 & $1.54-11.9$ & 0.004 \\
Systolic blood pressure (per mmHg) & 0.98 & $0.96-1.00$ & 0.09 \\
Diastolic blood pressure (per mmHg) & 1.00 & $0.96-1.04$ & 0.97 \\
Fasting blood glucose (per mg/dl) & 1.02 & $1.01-1.04$ & 0.004 \\
Total cholesterol (per mg/dl) & 1.01 & $1.00-1.02$ & 0.19 \\
HDL cholesterol (per mg/dl) & 0.95 & $0.92-0.98$ & $<0.001$ \\
Triglycerides (per mg/dl) & 1.01 & $1.00-1.01$ & 0.02 \\
Aspirin (yes) & 2.57 & $1.20-5.64$ & 0.01 \\
Statins (yes) & 1.61 & $0.78-3.36$ & 0.20 \\
Beta blockers (yes) & 1.78 & $0.85-3.77$ & 0.13 \\
ACE-I or ARB (yes) & 1.47 & $0.69-3.13$ & 0.32 \\
Nitrate (yes) & 0.77 & $0.30-1.94$ & 0.57 \\
Anti-diabetic drugs (yes) & 2.64 & $0.97-7.97$ & 0.06 \\
10 years FRS (per \%) & 1.08 & $1.03-1.14$ & $<0.001$ \\
Ln_RHI (per 0.1 decrease) & 1.30 & $1.12-1.54$ & $<0.001$ \\
\hline
\end{tabular}

ACE-I: angiotensin-converting enzyme-inhibitors, ARB: angiotensin II receptor blockers, CAD: coronary artery disease, CI: confidence interval, FRS: Framingham Risk Score, HDL: high density lipoprotein, OR odds ratio, and RHI: reactive hyperemia-peripheral arterial tonometry index. 


\section{Table 3}

Multivariate Logistic regression analysis for the presence of CAD.

\begin{tabular}{llll}
\hline & OR & 95\% CI & P \\
\hline Multivariate (Model-1) & & & \\
\hline Ln_RHI (per 0.1 decrease) & 1.25 & $1.04-1.52$ & 0.01 \\
\hline Multivariate with adjustment for FRS & & \\
\hline 10 years FRS (per \%) & 1.09 & $1.03-1.15$ & 0.001 \\
\cline { 2 - 4 } Ln_RHI (per 0.1 decrease) & 1.30 & $1.12-1.54$ & $<0.001$ \\
\hline
\end{tabular}

CAD: coronary artery disease, CI: confidence interval, FRS: Framingham Risk Score, OR odds ratio, and RHI: reactive hyperemia-peripheral arterial tonometry index. 


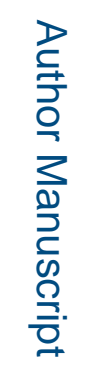

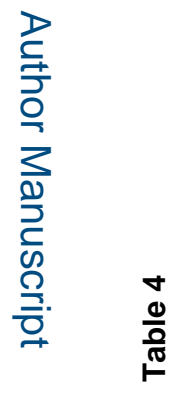

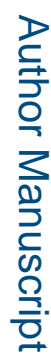

\begin{tabular}{|c|c|c|c|c|}
\hline a & $\bar{\delta}$ & $\begin{array}{l}\bar{\Delta} \\
\dot{\nabla}\end{array}$ & $\begin{array}{l}m \\
\stackrel{m}{0} \\
\dot{0}\end{array}$ & $\begin{array}{l}\mathscr{\delta} \\
0 \\
0\end{array}$ \\
\hline J & $\begin{array}{l}\hat{o} \\
0 \\
1\end{array}$ & 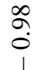 & & $\begin{array}{l}\vec{i} \\
0 \\
i\end{array}$ \\
\hline$\dddot{~} \dddot{\alpha}$ & సิ & ڤ్లి & $\overline{0}$ & $\begin{array}{l}0 \\
\dot{i}\end{array}$ \\
\hline
\end{tabular}

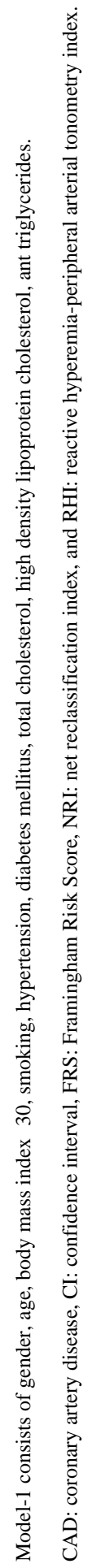

Dํ.

\begin{tabular}{|c|c|c|c|c|c|c|}
\hline $\begin{array}{l}\bar{z} \\
\bar{z} \\
\overline{\widetilde{z}} \\
\overline{\tilde{J}} \\
\bar{\sigma}\end{array}$ & & $\begin{array}{l}\tilde{b} \\
0 \\
0\end{array}$ & 声 & & 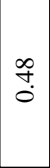 & $\tilde{m}$ \\
\hline 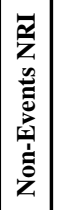 & & 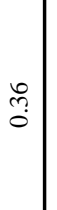 & 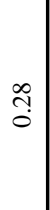 & & さ্ & $\frac{n}{0}$ \\
\hline 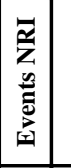 & & $\begin{array}{l}\text { प̦ } \\
\text { | }\end{array}$ & के & & ָุ & స్తి \\
\hline$\frac{\Phi}{\bar{\Xi}}$ & 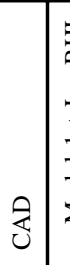 & 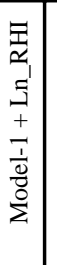 & 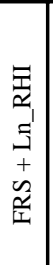 & 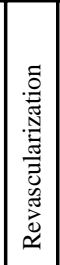 & 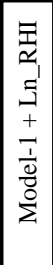 & 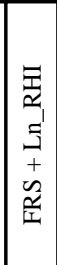 \\
\hline
\end{tabular}
Coron Artery Dis. Author manuscript; available in PMC 2016 May 01. 